УДК $781+78.01 / .072$

DOI https://doi.org/10.31723/2524-0447-2019-29-2-9

Сергей Витальевич Тышко

ORCID: 0000-0001-5283-1293

доктор искусствоведения, профессор

Национальной музыкальной академии Украины имени П. И. Чайковского

svstysh@gmail.com

\title{
СЛУЧАЙНАЯ ЗАКОНОМЕРНОСТЬ ИЛИ ЗАКОНОМЕРНЫЕ СЛУЧАЙНОСТИ? (О РОЛИ НЕКОТОРЫХ БИОГРАФИЧЕСКИХ ДЕТАЛЕЙ В ИСТОРИИ МУЗЫКАЛЬНОЙ КУЛЬТУРЫ)
}

Цель статьи - последовательно обосновать диалектический характер взаимодействия закономерного и случайного в событийном плане культуры, в судьбе музыкального искусства и отдельных художественных личностей, в частности, в творческой судьбе Николая Метнера и некоторых других представителей русской музыкальной традиции. Методология статьи определяется единством нарративного и биографического подходов, включенных в исторические проекции эпистемологии, с привлечением некоторых контекстуальных подходов и характеристик. Научная новизна исследования обусловлена внедрением метода микроисторического анализа, позволяющего обнаруживать, что в истории музыки случайности выступают катализаторами закономерных процессов, забегая впереди закономерностей, неуклонно к ним ведут; углублением биографического метода музыкально-культурологического исследования, позволяющим разделять и сопоставлять два основных плана жсизненно и художественно значимых событий, фактом общекультурного назначения и личностно-психологического содержания. Выводы подтверждают, что и случайности, и закономерности музыкально-исторического процесса следует изучать, как минимум, в двух направлениях, которые взаимно пересекаются: в собственно биографическом - с привлечением самых разнообразных контекстов (географического, исторического, политического, культурологического, медицинского и прочих) - и в общем музыкально-историческом (от замыслов и смыслов до интонационного генезиса и строения музыкальных произведений). Подтверждается также особая важность пересечения закономерного и случайного как иенностных измерений художественной фактографии в творческой биографии Николая Метнера и некоторых других представителей русской музыкальной культуры.

Ключевые слова: музыкальная культура, закономерность, случайность, биографический факт, музыкально-исторический прочесс, творческая судьба Николая Метнера.

(C) Тышко C. B., 2019 
Tyshko Serhei Vytalevych, Doctor of Arts, Professor of the Ukrainian National Tchaikovsky Academy of Music

Accidental regulation or regular cases? (on the role of some biographic details in the history of musical culture)

The purpose of the article is to reveal the dialectical nature of the interaction of natural and random in the fate of art and artistic personalities, in particular, in the creative fate of Nikolai Medtner and some other representatives of the Russian musical tradition. The methodology of the article is determined by the unity of narrative and biographical approaches included in the historical projections of epistemology, with the involvement of some contextual approaches and characteristics. The scientific novelty of the study is due to the introduction of the method of microhistorical analysis, which allows us to discover that in the history of music, randomness acts as a catalyst for regular processes, running ahead of regularities, steadily leads to them; the deepening of the biographical method of musical and cultural research, which allows us to separate and compare two basic plans of vital and artistically significant events, by the fact: general cultural purpose and personal psychological content. Conclusions confirm that the randomness and patterns of the musical-historical process should be studied in at least two directions that intersect each other: in the biographical proper, involving a wide variety of contexts (geographical, historical, political, cultural, medical, etc.) and in general musical and historical (from intentions and meanings to intonational genesis and structure of musical works). The special importance of the intersection of regular and random as value dimensions of artistic factography in the creative biography of Nikolai Medtner and some other representatives of Russian musical culture is also confirmed.

Key words: musical culture, regularity, randomness, biographical fact, musical and historical process, creative fate of Nikolai Medtner.

Тишко Сергій Віталійович, доктор мистеитвознавства, професор Національної музичної академії України імені П. І. Чайковського

Випадкова закономірність чи закономірність випадковості? (про роль деяких біографічних деталей в історії музичної культури)

Мета статті-розкрити діалектичний характер взаємодії закономірного й випадкового в долі мистеитва й художніх особистостей, зокрема у творчій долі Миколи Метнера й деяких інших представників російської музичної традиції. Методологія статті визначається єдністю наративного й біографічного підходів, включених в історичні проєкції епістемології із залученням деяких контекстуальних підходів і характеристик. Наукова новизна дослідження зумовлена впровадженням методу мікроісторичного аналізу, що дозволяе виявляти, яким чином в історії музики випадковості виступають каталізаторами закономірних процесів, забігаючи попереду закономірностей, неухильно до них ведуть; поглибленням біографічного методу музично-культурологічного дослідження, що дозволяє розділяти й зіставляти два основних плани життєво й художньо значущих подій, фактів загальнокультурного призначення та особистісно-психологічного змісту. Висновки підтверджують, 
що й випадковості, й закономірності музично-історичного процесу слід вивчати, як мінімум, у двох напрямках, що взаємно перетинаються: $у$ власне біографічному - із залученням найрізноманітніших контекстів (географічного, історичного, політичного, культурологічного, медичного й інших) - $і$ в загальному музично-історичному (від задумів і смислів до інтонаційного генезису й будови музичних творів). Підтверджується також особлива важливість перетину закономірного й випадкового як ціннісних вимірів художньої фактографії у творчій біографії Миколи Метнера й деяких інших представників російської музичної культури.

Ключові слова: музична культура, закономірність, випадковість, біографічний факт, музично-історичний процес, творча доля Миколи Метнера.

Актуальность темы статьи. В статье я не буду надолго останавливаться на сложных в философском смысле взаимоотношениях случайности и необходимости - т. е. закономерности. Иногда говорят, что необходимость играет главную, а случайность - второстепенную роль. Но я-то как раз и хочу показать, как случайности в комплексе их действия - иногда подспудно и изначально почти незаметно - становятся закономерностями в жизни музыкантов! Потому-то в этих диалектических хитросплетениях я ухвачусь лишь за одну очень важную мысль. Дело в том, что нередко случайность становится путем превращения возможности в действительность, предполагающим множество вариантов осуществления. Для примера: у Стефана Цвейга случайность бьется с судьбой (или с закономерностью?) в каждой новелле его мудрой книги «Звездные часы человечества». Цепи случайностей, иногда роковых, иногда счастливых преследуют ее героев - капитана Скотта, открывшего Антарктиду, или маршала Груши с его проигранным Ватерлоо, или Руже де Лиля, однажды ночью сочинившего музыку к «Марсельезе» [16]. Но закономерность нередко так случается! - оказывается сильнее целого сонма случайностей. Так и вышло с несчастным, промедлившим с решающим сражением маршалом Груши. Спустя столетие Цвейг написал об этом: «Если бы у Груши хватило мужества, если бы он посмел ослушаться приказа, если бы он поверил в себя и в явную, насущную необходимость, - Франция была бы спасена» [16]. Однако складывается впечатление, что не только в истории войн, но даже и в мирной истории музыки случайности не только словно забегают впереди закономерностей, но неуклонно к ним ведут! 
И еще не менее важно: в итоге реализуется лишь один из возможных вариантов событий. Как, например, у Германа Гессе в романе «Степной волк». Он пишет о случайной встрече с женщиной «с необыкновенными темно-карими глазами под льняными локонами», рядом с которой когда-то «простоял четверть часа в коридоре вагона скорого поезда». И завершает наблюдение так: «Я удивлялся тому, как богата была моя жизнь, моя на вид такая бедная и безлюбовная волчья жизнь, влюбленностями, благоприятными случаями, соблазнами. Я их почти все упускал, почти ото всех бежал, $<\ldots>$ забывал их как можно скорее, - а тут они все сохранились, без единого пробела, сотнями». И еще оттуда же: «Тысячи таких возможностей его ждут, его судьба непреодолимо влечет их <..> Достаточно пустяка, чтобы ударила молния» [2, с. 21]. Таким образом, речь идет об альтернативности и вариантности жизненного потока. А она, в свою очередь, дает возможность для игры случайностей и закономерности. Причем случайным будет подбор этих тысяч вариантов, но закономерным станет только один: тот, который свершится. То ли по воле истории, то ли по воле Божьей, то ли волевым усилием самого человека. Это и есть итог и главная закономерность. Этот процесс задевает любую творческую биографию и заставляет пристальнее приглядеться к случайностям.

Цель статьи - последовательно обосновать диалектический характер взаимодействия закономерного и случайного в событийном плане культуры, в судьбе музыкального искусства и отдельных художественных личностей, в частности, в творческой судьбе Николая Метнера и некоторых других представителей русской музыкальной традиции.

Научная новизна исследования обусловлена внедрением метода микроисторического анализа, позволяющего обнаруживать, что в истории музыки случайности выступают катализаторами закономерных процессов, забегая впереди закономерностей, неуклонно к ним ведут; углублением биографического метода музыкально-культурологического исследования, позволяющим разделять и сопоставлять два основных плана жизненно и художественно значимых событий, фактом общекультурного назначения и личностно-психологического содержания.

Основное содержание работы. Возникает вопрос: не слишком ли узко поле, не мелковата ли вода для нашего поиска закономерностей? Думаю, что оснований для сомнений здесь 
нет. Наша уверенность подкрепляется в этом случае методом микроисторического анализа. Сейчас этот метод, в свое время разработанный итальянскими историками Джованни Леви и Карло Гинзбургом [3, с. 321-345; 11, с. 119-138], успешно применяет моя аспирантка Е. Павелко в исследовании городской среды Варшавы середины XIX века и ее влиянии на мироощущение Михаила Глинки, давая при этом и концентрированное изложение его сущности ${ }^{1}$. Представляется вполне уместным применить этот метод и в статье. Кратко обозначу его важнейшие параметры: это локализация масштаба анализа, сосредоточение на ранее не замеченных подробностях и тонкостях, и как результат - открытие новых данных, расширяющих представление о проблеме исследования и открывающих пути для дальнейших изысканий.

А теперь к герою нашей дискуссии - Николаю Карловичу Метнеру. Представляется, что совсем не случайно одна из недавно опубликованных статей, посвященных ему, называется «Свобода сюжетной драматургии под эгидой порядка: (соната-баллада ор. 27 Н. Метнера)». И опубликована она в сборнике с симптоматическим названием: «Концепты хаоса и порядка в естественных и гуманитарных науках» [1, с. 466-470]. Приведу здесь и собственный пример того, как хаос и порядок сталкивались в жизни Метнера. Однажды его путь по европейскому континенту вроде бы случайно пересекся с C.В.Рахманиновым. Случилось это во Флоренции. Оба оказались там одновременно, весною 1924 года. И вот важная деталь: гармоничность и упорядоченность Ренессанса не могла не восхитить Николая Карловича, Флоренция тогда произвела на него действительно сильное и безусловно позитивное впечатлениебез всяких колебаний! Чего не скажешь о Чайковском и Рахманинове, которые постигали красоту этого города, преодолевая некоторые противоречия.

Здесь мы уже видим след закономерности. Пойдем по нему дальше. Одно из многочисленных свидетельств того, как восторженно воспринимал Флоренцию Метнер, принадлежит Альфреду Альфредовичу Свану. Он вспоминал: «В 1950 году мы с женой путешествовали по Италии, и Николай Карлович [Метнер] словно бы сопровождал нас своими всевозможными шутливыми наставлениями, как нам действовать в любимой им

$\overline{{ }^{1} \text { См. подробнее: }}[14]$. 
Флоренции. Отыскав где-то вид этого города, он послал его нам, исписав открытку всеми ему известными итальянскими названиями вроде: «Cosi fan tutti e tutti frutti»; пометил датой, когда он сам ездил во Флоренцию («Primavera, 1924») и подписал: «Nicolo Metnereccio (Метнереччьо»)» [15]. Действительно, Метнер был в покорен Флоренцией и считал ее лучшим местом для отдыха и забвения всех трудностей современной жизни. Но ведь мы знаем, что флорентийские рефлексии Рахманинова были значительно более сдержанными.

Однако, несмотря на различия двух композиторов в их флорентийском тонусе, встреча прошла в полном согласии, и Метнер вспоминал о ней: «Я очень много вынес там из совместного пребывания с Сергеем Васильевичем. Мне удалось за это время несколько ближе подойти к этому воистину живому человеку и художнику» [12, с. 273]. А супруга композитора, Анна Михайловна, так писала о помощи Рахманинова с концертным туром по Америке, судьбу которого оба композитора решали при встрече: «[Сергей Васильевич] с таким рвением уходит в это, так о Коле заботится, что, право, иногда можно подумать, что это больше касается его, чем Коли» [12, с. 269].

Что же касается Чайковского, то его восприятие итальянских городских пейзажей и вовсе пребывало в перманентном противоречии. Здесь даже более показательно выглядит его высказывание о другой жемчужине Италии - Венеции: «... Холод здесь ужасный, и это мне нравится, потому что итальянскую жару я испытал в прошлом году <..> Я с трудом нашел комнатку, притом весьма невзрачную <..> Венеция такой город, что если бы пришлось здесь прожить неделю, то на пятый день я бы удавился с отчаяния. Все сосредоточено на площади св. Марка. Куда ни пойдешь, пропадешь в лабиринте вонючих коридоров, никуда не приводящих, и пока не сядешь где-нибудь в гондолу и не велишь себя везти, не поймешь где находишься» [17, с. 202]. При этом Петр Ильич остался вполне удовлетворенным Canale Grande и вовсе пришел в восторг от Дворца Дожей («верх красоты и интересности, с романтическим ароматом»). Но не преминул заметить, что дворцы один грязнее и запущеннее другого. И все же резюмировал: «Город мрачный, как будто вымерший» $[17$, с. 202]². Такая реакция

${ }^{2}$ Путевые впечатления русских композиторов в городах Италии и в других странах сейчас активно изучает моя студентка Е. Миненко (класс по специальности в НМАУ им. П. И. Чайковского). 
тоже выглядит вполне закономерной, если вспомнить о том, что писал о Венеции Гоголь: «Стои́т Венеция, отразив в адриатические волны свои потухнувшие дворцы, и разрывающей жалостью проникается сердце иностранца, когда поникший гондольер влечет его под пустынными стенами и разрушенными перилами безмолвных мраморных балконов» [6, с. 209]. Кстати, Томасу Манну гондолы и вовсе напоминали гробы («Смерть в Венеции»). Да, поистине загадочный город!

Замечу, что рекомендации путешественникам в письмах Н.К. Метнера очень напоминают о наставлениях по поводу Италии и Испании, которые М.И. Глинка давным-давно давал В.П. Энгельгардту [5, с. 2892-2893]: эти советы автора «Руслана» еще раз свидетельствуют о стремлении к «отчетливости», «докладности» и прочим когда-то заявленным им важнейшим аксиологическим критериям. Вообще же привычка давать наставления путешественникам прочно вошла в путевые заметки, мемуаристику и эпистолярий художников романтической и даже послеромантической эпохи; примерам несть числа, и вот она - закономерность! Причина здесь в том, что композиторы, литераторы и художники жадно овладевали пространствами. Причем нередко предпочитали приветствовать их или прощаться с ними, обозревая новую страну с горных вершин - будь то Пиренеи, или Альпы, или Кавказ. Вспомним здесь «Горные вершины» с замечательными интерпретациями текста Гёте у Лермонтова и в романсе Варламова. Весьма вероятно, что горное ощущение высоты, вертикали влияло на будущие художественные замыслы, на музыкальные идеи, как бы поднявшиеся над сюжетными коллизиями ввысь, под облака, на остановки-зависания, когда музыкальная мысль словно переходит в другие измерения. Небо-то в горах казалось ближе... И это тоже безусловная закономерность.

В начале XX века П. Муратов в книге «Образы Италии» поэтично поведал о прощании с этой страной в веронских садах Джусти: «В этих садах <..> сколь многие из северных людей приветствовали впервые Италию и <...> прощались здесь с ней. Путешественники XVII и XVIII века упоминают о них в своих важных или легкомысленных мемуарах, современные туристы бросают в почтовый ящик свои первые или последние итальянские открытки с видом их многостолетних кипарисов» [13, с. 523].

Коль скоро мы вновь попали в Италию, не могу не упомянуть о подзабытом факте, привлекшем мое внимание при 
изучении странствий М.Глинки по Апеннинскому полуострову в начале 30-х годов прошлого века. Речь идет о неожиданном маршруте, который композитор избрал при возвращении из Рима в Милан: сухим путем, вдоль восточного побережья Италии - в частности, через города Анкона и Болонья. Интересно, почему он не поплыл пароходом вдоль западного берега полуострова, как за год с небольшим до этого добирался в Рим? Ведь такой путь кажется более логичным и легким! Оказывается, к этому выбору подталкивали синхронно происходившие военно-политические события: в 1831 году австрийцы вторглись в Папскую Область, а французы в противовес им в феврале 1832 г. заняли Анкону с ее крепостью. Замечательно то, что путь Глинки пролегал именно через Анкону и был пройден как раз во второй половине февраля или в начале марта 1832 года'! И по той же дороге и в то же время Глинка проезжал Модену, где в 1831 г. совершилась настоящая революция, но некоторое время спустя город заняли австрийцы. Добавим сюда и жесткие столкновения с австрийцами в Болонье, которую тогда же не смог миновать Михаил Иванович. Казалось бы, биографическая случайностьвыбор не самой удачной и безопасной дороги? Но тут неожиданно накручивается целая цепь неожиданных аналогий: не слишком ли часто Глинка оказывается в нужное время в нужном месте, в «горячих точках»? Добавим сюда охваченный революцией (pronunciamiento) Мадрид в 1845-м, или поездку на Кавказ - еще в 1823-м по пути, буквально сотрясаемом набегами горцев, или странный заезд украинский Переяслав в 1838-м, в самый разгар «винного бунта», или присутствие на постановке «Армиды» Глюка в Берлине, стоявшем буквально на грани войны с Россией весной 1854-го. Подобные примеры можно множить и множить. А если мы еще вспомним о тесном общении с российским дипломатом Ремером прямо перед поездкой по опасной анконской дороге (Marchi d'Ancona), приходят в голову самые фантастические предположения... В чем же тут закономерность? На мой взгляд, в том, что Глинка мало того, что не избегал подобных опасностей, но иногда даже (создается такое впечатление!) стре-

\footnotetext{
${ }^{3}$ Основание - письмо Зинаиде Волконской из Неаполя от 11/23 февраля 1832 г., где Глинка сообщал: «Через несколько дней я уезжаю отсюда и направляюсь в Милан» [4, с. 40-41], а также упоминание в «Записках» М.И. Глинки о том, что он прибыл в Милан в начале марта.
} 
мился к ним. При этом всегда действовал с осторожностью, по его словам, «в меру, а не чрез меру», почему и оставался жив и невредим, иногда чудом! И ведь не случайно забегает на итальянские страницы «Записок» композитора некий «nлохой тенор», спасший его стаканом ромашки от тяжелых последствий отравления в соседнем трактире, и таким образом ставший своеобразным антиподом Сальери.

А теперь перенесемся из Европы в Америку, следуя по путям пианиста Владимира Горовица. Казалось бы, девятилетний Володя Горовиц случайно попадает на концерт С.В. Рахманинова в Киеве. И что же происходит? «Я сразу отождествил себя с Рахманиновым. Он играл концерты из собственных сочинений, которые я слушал в 9 или 10 лет»,- через много лет вспоминал пианист [18, с. 48-49]. А двенадцать лет спустя Рахманинов слушает в нью-йоркском Карнеги-холл Владимира Горовица именно с его Третьим фортепианным концертом. И в ночь после события пишет Горовицу пространное и теплое письмо. (Мы с Ю.А. Зильберманом в 2007 году подробно прокомментировали его и ввели в научный оборот [9]). Случайность? Но посмотрим, что было в промежутке между этими событиями... Находим несколько информационных поводов, буквально подталкивавших Рахманинова обратить внимание на юного Горовица. Вот лишь один из них. Речь идет о письме Феликса Блуменфельда, направленном Рахманинову в Америку еще в 1920 г. Там говорится о том, что вПлоть до этого года в его классе учился Владимир Горовиц - чрезвычайно талантливый студент, «поклонник музыки Рахманинова и Метнера» ${ }^{4}$. Вот и выстраивается вполне закономерная музыкально-историческая связь: Рахманинов-Метнер - Горовиц. Напомню, что Рахманинов считал Владимира Самойловича лучшим исполнителем его Третьего концерта. А ведь первое «живое» общение Рахманинова и Горовица состоялось еще за четыре дня до знаменитого концерта в Карнеги-холл в январе 1928 г. В свое время мы выяснили, где предположительно происходила эта встреча, и что собственно игралось в тот день то ли в маленькой нью-йоркской квартире Рахманинова, то ли знаменитом в подвале, где хранились концертные рояли компании «Steinway». Оказалось, что вероятно это несколько сочинений Метнера, сыгранных

${ }^{4}$ См.: [9]. 
сначала Рахманиновым, а потом Горовицем [9]. Это было отнюдь не случайным выбором, потому что, во-первых, Метнер был в числе близких друзей Рахманинова, а во-вторых, потому что Горовиц любил играть его музыку. Существует и такое предположение: Горовиц и Рахманинов играли тогда все тот же Третий концерт. Если это так, то здесь сталкиваемся с первым зафиксированным фактом их совместного музицирования. В дальнейшем оно приобретет характер традиции и придет к своей «кульминации» на даче в Беверли-Хиллз, в самый тяжелый период Второй мировой войны, летом 1942 года. А играли они «Симфонические танцы» Рахманинова в только что созданном автором фортепианном переложении. И ведь именно там, в Финале, словно из недр темы Dies irae, вырастает богослужебный напев рахманиновского «Всенощного бдения» - «Благословен еси, Господи, научи мя оправданием Твоим». Это песнопение повествует о чуде Воскресения и своей мощной поступью противостоит в смысловой драматургии «Симфонических танцев» вселенскому злу. Этой гениальной реминисценцией Рахманинов дает надежду тысячам и тысячам своих слушателей в самых разных уголках мира. Вспомним: надежда, по словам А.С.Пушкина - «несчастью верная сестра». В этом, пожалуй, главная закономерность!

И еще об одной случайности, перерастающей в закономерность. В 1951 году вдова Н. Метнера, Анна Михайловна, в письме Владимиру Самойловичу Горовицу величает его «Владимиром Сергеевичем»- правда, сомневаясь, «правильно ли помнит его отчество» [10, с. 94]. И все бы ничего, если бы это был единичный случай подобной путаницы. Михаил Чехов, прекрасно знавший Владимира Самойловича, в те же послевоенные годы на протяжении короткого письма умудряется пять раз назвать Горовица Владимиром Семеновичем [7]. А завершает картину известный пианист Владимир Ашкенази, который уже в 1965-м величал Горовица и вовсе Владимиром Израилевичем (!) [7]. Напомню, что в те далекие времена Горовицу уже глубоко под пятьдесят, а то и за шестьдесят, и он всемирно известен! Так отчего же случился и повторялся подобный курьез? Мы с Ю.А. Зильберманом в свое время поинтересовались, какое отчество Горовица значится в его советском паспорте, выданном в 1925 году. И очень удивились, прочитав там запись «Владимир Семенович» [7; 8]. Вообще же многое наводит на мысль о возможном исполь- 
зовании «паспортного» отчества в эмигрантском окружении пианиста. И это уже некая закономерность, причину которой пока не удается разгадать. Разве что такая: возможно, в жизни Рахманинова чаще величали по отчеству, а Горовица и в жизни, и тем более в концертной практике - просто Владимиром, не добавляя отчества?

А теперь от загадочного - и к вовсе фантасмагорическому. О том, как Горовиц в 1986 году, то есть за три года до смерти, пишет письмо Петру Ильичу Чайковскому, адресованное прямо «на кладбище в Ленинграде». Причем в номере той же гамбургской гостиницы, где останавливался во время своего первого европейского триумфа 1928 года с Фортепианным концертом Чайковского 5 . Чем не парадокс? И вновь складывается некая «неслучайная закономерность».

Выводы. Итак, и случайности, и закономерности музыкально-исторического процесса следует изучать как минимум в двух направлениях, которые взаимно пересекаются: (1) в собственно биографическом - с привлечением самых разнообразных контекстов (географического, исторического, политического, культурологического, медицинского и проч.) и (2) в общем музыкально-историческом (от замыслов и смыслов до интонационного генезиса и строения музыкальных произведений).

И в заключение. Я не могу сейчас определить теоретическую ценность моего сообщения, потому что многого не знаю, не знаю до конца и того, в каком виде существует в действительности диалектика случайного и закономерного, и даже того, что ведали о таковой Сергей Рахманинов, или Михаил Глинка, или Владимир Горовиц. Разве что Николай Метнер? Но вот что я предчувствую - так это то, что биографические факты упрямы и выдают подчас такие совпадения и судьбоносные мелочи, что диву даешься...

\section{СПИСОК ЛИТЕРАТУРЫ}

1. Бажина Н. Свобода сюжетной драматургии под эгидой порядка: (соната-баллада ор. $27 \mathrm{H}$. Метнера). Концепты хаоса и порядка в естественных и гуманитарных науках $=$ Konzepte von chaos und ordnung in natur- und geisteswissenschaften: Национальное исследование ун-т «Высшая школа экономики», Нижегор. фил., Австрийская б-ка Нижнего Новгорода / под ред. В. Ахамер и др. Нижний Новгород : ДЕКОМ, 2011. С. 466-470.

${ }_{5}^{5}$ См. подробнее: [9]. 
2. Гессе Г. Степной волк / пер. С.Апта. URL: http://www.hesse.ru/ books.

3. Гинзбург К. Мифы - эмблемы - приметы: Морфология и история / пер. с итал. и послесл. С.Козлова. Москва : Новое издательство, 2004. С. 321-345.

4. Глинка М. Письмо 3.А.Волконской 11/23 февраля 1832 г. Полное собрание сочинений. Литературные произведения и переписка : в 2-х т. Т. 2а / подгот. А. Ляпунова. Москва : Музыка, 1975. С. 40-41.

5. Глинка М. Записка для путешествия В.П. Энгельгардта. Письма и документы. Ч. ІІ: Деловые бумаги и прочие документы. Приложсения. Комментарии и указатели. Москва : Директ-Медиа, 2012. C. $2892-2893$.

6. Гоголь Н. Рим (отрывок). Собрание сочинений : в 6-ти тт. T. 3: Повести. Москва : Гос. издательство худ. литературы, 1949. C. $186-228$.

7. Зильберман Ю., Тышко С. «Может быть, Владимир Семенович захочет помочь...». (Комментарии к неизвестному письму М.А. Чехова В.С. Горовицу). Київське музикознавство. Культурологія та мистецтвознавство. Вип. 32. Київ : 2010. С. 252-268.

8. Зильберман Ю., Тышко С. Владимир Горовиц на родине и в эмиграции. Биографическая реальность - искаженная и восстановленная. (Работа над ошибками). Київське музикознавство. Вип. 25: Культурологія та мистецтвознавство. Київ : 2007. С. 221-237.

9. Зильберман Ю., Тышко С. Владимир Горовиц: от Чайковского к Рахманинову. (Пять комментариев к малоизвестному письму С.В. Рахманинова В.С. Горовицу). Музыкальная академия. 2007. № 2. C. $125-150$.

10. Зильберман Ю. Русская корреспонденция Владимира Горовица в архиве Йельского университета. Мюнхен : 2019. 173 с. URL: https://issuu.com/horowitzpianocompetition/docs/9dd644488c8bfb.

11. Леві Дж. Про мікроісторію. Нові підходи до історіописання: збірник статей / ред. П. Берка. Київ : Ніка-Центр, 2010. С. 119-138.

12. Метнер Н. Письма / сост. З. Апетян. Москва : Советский композитор, 1973. $650 \mathrm{c.}$

13. Муратов П. Образы Италии. Москва : Республика, 1994. 592 с.

14. Павелко К. Мікроісторичний метод дослідження творчої біографії композитора (на прикладі варшавського періоду життя Михайла Глінки). Часопис Національної музичної академії України імені П. І. Чайковського. Київ : 2017. С. 68-78.

15. Сван А. Мои встречи с истинным художником. Воспоминания о Метнере. URL: http://www.nikolaimedtner.ru/memoirs/swan.html

16. Цвейг Стефан. Звездные часы человечества. Москва : АСТ, 2009. $192 \mathrm{c}$.

17. Чайковский П. Письмо М.И.Чайковскому от 17/29 апреля 1874 г. Письма к родным / ред. и примечания В. Жданова. Т. 1: 18501879. Москва : Государственное музыкальное издательство, 1940. C. 201-202. 
18. Shonberg H. Horowitz. His life \& music. London, Simon \& Shuster Ltd, 1992. $432 \mathrm{p}$.

19. Silberman J., Tyschko S. Wladimir Horowitz im Vaterland und in der Emigration. Biographische Realitдt - entstellt und wiederhergestellt (Fehlerberichtigung). Київське музикознавство. Вип. 28: Musikwisseschaft im Dialog. Київ - Dьsseldorf, 2008. С.76- 88.

\section{REFERENCES}

1. Bazhina, N. N. (2011). Freedom of plot dramaturgy under the auspices of order: (sonata ballad Op. 27 N. Metner) // Concepts of chaos and order in the natural sciences and the humanities = Konzepte von chaos und ordnung in natur- und geisteswissenschaften / [Nat . researched University "Higher School of Economics», Nizhegor. fil.], Austrian b-ka of Nizhny Novgorod; [ed. B. Achamer and others.]. Nizhny Novgorod: DECOM, P. 466-470 [in Russian].

2. Hesse, G. Steppe wolf / trans. S. Apta / http://www.hesse.ru/books [in Russian].

3. Ginzburg, K. (2004). Myths - emblems - signs: Morphology and history / trans. with ital. and after S. L. Kozlova. Moscow: New Publishing House, P. 321-345 [in Russian].

4. Glinka, M.I. (1975). Letter from Z.A. Volkonskaya February 11/23,// Glinka M.I. Full Sobr. Op. Literary works and correspondence: in 2 volumes T. 2a. [prepare. A.S. Lyapunov]. M.: Music, P. 40-41 [in Russian].

5. Glinka, (2012). Note for travel V.P. Engelhardt // Glinka M. Letters and documents. Part II: Business papers and other documents. Applications Comments and pointers. M .: Direct Media, P. 2892-2893 [in Russian].

6. Gogol, N.V. (1949). Rome (excerpt) // Gogol N.V. Sobr. Op. In 6 vols. T. 3: Tales. $M \quad \therefore$ State. publishing house is thin. Literature, P. 186-228. [in Russian].

7. Zilberman, Yu., Tyshko S. (2010). "Maybe Vladimir Semenovich wants to help...". (Comments on the unknown letter of M.A. Chekhov to V.S. Horowitz) // Kiev Musicology. Culturology and mystic exaltation. Vip. 32. K.: P. 252-268 [in Russian].

8. Zilberman, Yu., Tyshko S. (2007). Vladimir Horowitz at home and in exile. Biographical reality is distorted and restored. (Work on the bugs) // Kyiv Musical Studies. Vip. 25: Culturology and mystic exaltation. K.: P. 221-237 [in Russian].

9. Zilberman, Yu., Tyshko S. (2007). Vladimir Horowitz: from Tchaikovsky to Rachmaninov. (Five comments on the little-known letter of S.V. Rachmaninov to V.S. Horowitz) // Musical Academy. No. 2. P. 125-150 [in Russian].

10. Zilberman Yu.A. (2019). Russian correspondence of Vladimir Horowitz in the archives of Yale University. Munich: URL: https://issuu. com/horowitzpianocompetition/docs/9dd644488c8bfb [in Russian].

11. Lev, J. (2010). About the history // New approaches to history: zb. Art. / ed. P. Burke. Kiev: Nika-Center, P. 119-138 [in Russian]. 
12. Metner, N.K. (1973). Letters / Comp. BEHIND. Apetian. M.: Soviet composer [in Russian].

13. Muratov, P.P. (1994). Images of Italy. M.: Republic [in Russian].

14. Pavelko, K. (2017). Micro-historical method of composing a creative biography of the composer (on the application of the Warsaw period of life of Mikhail Glinka) Chronicle of the National Musical Academy of Ukraine imeni P. I. Tchaikovsky. K.: P. 68-78 [in Russian].

15. Svan, A.A. My meetings with a true artist // Memories of Metner http://www.nikolaimedtner.ru/memoirs/swan.html [in Russian].

16. Stefan, Zweig. (2009). The starry clock of humanity. M.: AST, 192 s. [in Russian].

17. Tchaikovsky, P.I. (1940). Letter to M.I. Tchaikovsky on April 17/29? 1874 // Tchaikovsky P.I. Letters to relatives / Ed. and notes by V.A. Zhdanova. T. 1: 1850-1879. M.: State Music Publishing House, P. 201-202 [in Russian].

18. Shonberg, H. (1992). Horowitz. His life \& music. London, Simon \& Shuster Ltd, [in English].

19. Silberman, J., Tyschko S. 2008. Wladimir Horowitz im Vaterland und in der Emigration. Biographische Realitzt - entstellt und wiederhergestellt (Fehlerberichtigung) // Kiev Musicology. Vip. 28: Musikwisseschaft im Dialog. K. Dısseldorf, C.76-88 [in English].

УДК 780.616.432.071.1(470):82

DOI https://doi.org/10.31723/2524-0447-2019-29-2-10

\author{
Ирина Степановна Драч \\ ORCID: 0000-0003-2089-9570 \\ доктор искусствоведения, профессор \\ Харьковского национального университета искусств \\ имени И. П. Котляревского \\ drach.irina2016@gmail.com

\section{ПОЛЕ ИЛЛЮЗИИ КОМПОЗИТОРСКОЙ ИНДИВИДУАЛЬНОСТИ НИКОЛАЯ МЕТНЕРА}

Цель статьи - осмысление музыки Н. Метнера как целостного феномена, позволяющее выявить в рамках художественной системы композитора обладающий повышенной смысловой нагрузкой образ. В качестве ключевого структурообразующего концепта он позволяет интерпретировать большинство метнеровских опусов как взаимоизо-

(С) Драч И. С., 2019 